\title{
Multilineage Differentiation Potential of Stem Cells Derived from Human Dental Pulp after Cryopreservation
}

\author{
WEIBO ZHANG, D.D.S., Ph.D., ${ }^{1}$ X. FRANK WALBOOMERS, Ph.D., ${ }^{1}$ \\ SONGTAO SHI, D.D.S., Ph.D., ${ }^{2}$ MINGWEN FAN, D.D.S., Ph.D., ${ }^{3}$ \\ and JOHN A. JANSEN, D.D.S., Ph.D. ${ }^{1}$
}

\begin{abstract}
The current study aimed to prove that human dental pulp stem cells (hDPSCs) isolated from the pulp of third molars can show multilineage differentiation after cryopreservation. First, hDPSC were isolated via enzymatic procedures, and frozen in liquid nitrogen until use. After defrosting, cells were analyzed for proliferative potential and the expression of the stem cell marker STRO-1. Subsequently, cells were cultured in neurogenic, osteogenic/odontogenic, adipogenic, myogenic, and chondrogenic inductive media, and analyzed on basis of morphology, immunohistochemistry, and reverse transcriptase-polymerase chain reaction (RT-PCR) for specific marker genes. All data were replicated, and the results of the primary cells were compared to similar tests with an additional primary dental pulp stem cell strain, obtained from the National Institutes of Health (NIH). Results showed that our cell population could be maintained for at least 25 passages. The existence of stem/ progenitor cells in both cell strains was proven by the STRO-1 staining. Under the influence of the 5 different media, both cell strains were capable to advance into all 5 differentiation pathways. Still differences between both strains were found. In general, our primary culture performed better in myogenic differentiation, while the externally obtained cells were superior in the odontogenic/osteogenic and chondrogenic differentiation pathways. In conclusion, the pulp tissue of the third molar may serve as a suitable source of multipotent stem cells for future tissue engineering strategies and cell-based therapies, even after cryopreservation.
\end{abstract}

\section{INTRODUCTION}

A DULT STEM CELLS (ASCs) situated in differentiated tissues have the potential to produce the specialized cell types to maintain and repair the tissue they reside in. ASCs have been isolated from many tissues ${ }^{1}$ such as bone marrow, ${ }^{2,3}$ brain, ${ }^{4}$ skin, ${ }^{5}$ muscle, ${ }^{6}$ and fat tissue. ${ }^{7}$ Previously, it was generally accepted that the differentiation potential of ASCs was lineage restricted. This hypothesis currently faces challenge as more and more evidence demonstrates that ASCs have the potential to cross lineage boundaries, and also are able to differentiate into specific cells of tissues beyond their origin. For instance, it has been confirmed that bone marrow stem cells have the ability to differentiate into neurons, ${ }^{8}$ osteoblasts, ${ }^{9}$ adipocytes, ${ }^{9}$ and myoblasts. ${ }^{10}$ Stem cells that have been isolated from other differentiated tissues such as brain, ${ }^{11}$ muscle, ${ }^{12}$ and fat tissue, ${ }^{13}$ also show similar multilineage potential. Currently, there is no well accepted definition of this property of ASCs; and it has been termed plasticity, ${ }^{14}$ trans-differentiation, ${ }^{15}$ or unorthodox differentiation. ${ }^{16}$ This finding increases the potential use of organ- or tissue-specific stem cells, because it suggests that stem cells can regenerate multiple tissues in different locations.

\footnotetext{
${ }^{1}$ Radboud University Nijmegen Medical Centre, Periodontology \& Biomaterials, Nijmegen, The Netherlands.

${ }^{2}$ National Institutes of Health/NIDCR, Bethesda, Maryland.

${ }^{3}$ Wuhan University, School of Stomatology, Wuhan, China.
} 
Recently, adult stem cells also have been isolated from the human dental pulp. ${ }^{17,18}$ In these studies, isolated cell populations from impacted wisdom teeth were proven to contain stem cells. Subsequent transplantation of human dental pulp stem cells (hDPSCs) in immunocompromised mice resulted in the formation of a dentin-pulp complexlike structure. To evaluate the differentiation potential of hDPSCs in other directions than strictly the odontogenic pathway, some analyses have been performed. Adipogenic and neurogenic directions were explored. ${ }^{17}$ It was shown that hDPSCs could express the adipocyte-specific markers Peroxisome-proliferating activated receptor $\gamma(\operatorname{PPAR} \gamma 2)$ and lipoprotein lipase after being cultured in adipogenic medium. Further, the expression of nestin and glial fibrillary acid protein (GFAP) was found, as markers of neural precursors and glial cells. ${ }^{18}$ Such findings suggest that human dental pulp derived stem cells may also have the potential to cross the lineage boundaries and produce cell types other than odontoblast. However, currently no systematic research has been done in which multilineage potential for neurogenic, odontogenic, adipogenic, myogenic, and chondrogenic differentiation have all been compared within one cell population. Also, many previous studies did not include a cryopreservation step in the cell culturing process. We hypothesize that all such differentiation pathways can be obtained from a single biopsy even after prolonged storage in liquid nitrogen. Therefore the specific aims of the current study were to retrieve primary hDPSCs and systematically evaluate the multilineage differentiation ability after cryopreservation.

\section{MATERIALS AND METHODS}

\section{Cell isolation and basic analysis}

All experiments were done observing national guidelines for working with human materials. Impacted third molars without caries or other dental problems were obtained from young adult patients (18-24 years of age). Each molar was always handled separately, and immediately after extraction placed in alpha-minimal essential medium ( $\alpha$-MEM; Gibco BRL, Life Technologies B.V. Breda, The Netherlands) with $0.5 \mathrm{mg} / \mathrm{mL}$ of gentamicin (Gibco BRL) and $3(\mathrm{~g} / \mathrm{mL}$ of amphotericin B (Gibco BRL). The tooth surface was cleaned, and a cut was made around the cementum-enamel junction using a high-speed dental drill. The pulp chamber was revealed and the pulp was taken out. Thereafter, the coronary part of the pulp was minced and digested with $3 \mathrm{mg} / \mathrm{mL}$ of collagenase type I for $1 \mathrm{~h}$ at $37^{\circ} \mathrm{C}$ with gentle shaking. A single-cell suspension was obtained by passing the complete digested solution through a $100-\mu \mathrm{m}$ strainer. The released cells were pelleted, seeded in culture flasks, and incubated at $37^{\circ} \mathrm{C}$ in $5 \%$ carbon dioxide, in $\alpha$-MEM culture medium with $20 \%$ fetal calf serum (FCS; Gibco BRL). The cells were then collected and stored in liquid nitrogen for at least 1 month before further analysis. After cryopreservation, all obtained dental pulp cell cultures were recovered and cultured in 80- $\mathrm{cm}^{2}$ culture flasks (Nalge Nunc International, Naperville, IL) in $\alpha$-MEM-10\% FCS.

For future tissue engineering purposes, it was essential to select a strain of cells with excellent proliferative and differentiation potential. Therefore, all obtained cell cultures were trypsinized after confluency and passaged repeatedly. Only cultures that could be maintained for 25 passages were selected. Of these cultures, passage 26 was subsequently grown in $\alpha$-MEM culture medium with $10 \% \mathrm{FCS}, 5 \mathrm{mmol} / \mathrm{L}$ of $\mathrm{KH}_{2} \mathrm{PO}_{4}, 50 \mu \mathrm{g} / \mathrm{mL}$ of L-ascorbic acid, and $50 \mu \mathrm{g} / \mathrm{mL}$ of gentamycin. After 3 weeks, von Kossa staining was performed as a final selection of the cells for further experimentation. In this way, only one cell strain that could proliferate stably for a long time while maintaining the ability of differentiation was selected for the further analyses. These primary cells were termed hDPSC-NB.

Besides the hDPSC-NB, also a selected strain of primary dental pulp cells from the National Institute of Health (NIH) was used. These cells have been described previously, ${ }^{17}$ and are called hDPSC-NIH in this study.

\section{Immunofluoresence for STRO-1}

hDPSC-NB and hDPSC-NIH were thawed, seeded on chamberslides (Nunc) at $4 \times 10^{4}$ cells $/ \mathrm{cm}^{2}$, and cultured overnight. After washing in phosphate-buffered saline (PBS; $\mathrm{pH}$ 7.4) and fixation in 4\% paraformaldehyde, cells were preincubated in 10\% goat serum for $15 \mathrm{~min}$, and incubated with mouse anti-human STRO-1 antibody (MAB1038, R\&D systems Inc. Minneapolis, MN) for $1 \mathrm{~h}$. Then, cells were incubated with Tetramethylrhodamine isothiocyanate (TRITC)conjugated goat antimouse IgM (CaT. NO. 115-026-020, Jackson ImmunoResearch Laboratories, West Grove, PA) for $45 \mathrm{~min}$. Slides were observed using fluorescence microscopy (Leica).

\section{Induction of differentiation lineages}

Cell were thawed and expanded. For all experiments, equal 4th passage cells of both strains were used. Five differentiation pathways were induced, by providing specific additives to the cell culture medium. Cells cultured in standard $\alpha$-MEM culture medium-10\% FCS-50 $\mu \mathrm{g} / \mathrm{mL}$ of gentamicin were used as a control group for all analyses. All samples for each parameter were presented in threefold except the chondrogenic pathway. To obtain enough RNA for reverse transcriptase-polymerase chain reaction (RTPCR), three wells were used, which were later pooled together. All analyses were duplicated, in a separate second run of the entire experiment.

- Neurogenic differentiation: Cells were seeded on 24-well plates at 20,000 cells $/ \mathrm{cm}^{2}$. Subconfluent cultures were maintained in $\alpha$-MEM-10\% FCS. After confluency, media were replaced with preinduction media (Table 1). After $24 \mathrm{~h}$, the cells were washed and neuronal induction medium (Table 1) was added. Samples were checked 
Table 1. Lineage-Specific Differentiation Inducing Media

\begin{tabular}{|c|c|c|c|}
\hline Medium & Media & Serum & Supplementation \\
\hline Neurogenic (NM) & $\alpha-\mathrm{MEM}$ & None & $\begin{array}{c}10 \mathrm{mM} \text { BME, } 2 \% \text { dimethyl sulfoxide (DMSO), } \\
200 \mu \mathrm{M} \text { butylated hydroxyanisole (BHA) }\end{array}$ \\
\hline Preinduction NM & $\alpha-\mathrm{MEM}$ & $10 \% \mathrm{FCS}$ & $1 \mathrm{mM} \beta$-mercaptoethanol (BME) \\
\hline Osteogenic (OM) & $\alpha-\mathrm{MEM}$ & $10 \%$ FCS & $\begin{array}{l}5 \mathrm{mmol} / \mathrm{L} \text { of } \mathrm{KH}_{2} \mathrm{PO}_{4}, 10^{-8} \mathrm{M} \text { dexamethasone, } \\
50 \mu \mathrm{g} / \mathrm{mL} \text { of L-ascorbic acid, } 50 \mu \mathrm{g} / \mathrm{mL} \text { of } \\
\text { gentamicin }\end{array}$ \\
\hline Adipogenic (AM) & $\alpha-\mathrm{MEM}$ & $10 \%$ FCS & $\begin{array}{l}0.5 \mathrm{mM} \text { isobutyl-methylxanthine (IBMX), } 1 \mu \mathrm{M} \\
\text { dexamethasone, } 10 \mu \mathrm{M} \text { insulin, } 200 \mu \mathrm{M} \\
\text { indomethacin, } 50 \mu \mathrm{g} / \mathrm{mL} \text { of gentamicin }\end{array}$ \\
\hline Myogenic (MM) & $\alpha-\mathrm{MEM}$ & $\begin{array}{l}10 \% \mathrm{FCS} \\
5 \% \mathrm{HS}\end{array}$ & $\begin{array}{l}0.1 \mu \mathrm{M} \text { dexamethasone, } 50 \mu \mathrm{M} \text { hydrocortisone, } \\
50 \mu \mathrm{g} / \mathrm{mL} \text { of gentamicin }\end{array}$ \\
\hline $\begin{array}{l}\text { Chondrogenic } \\
\text { (CM) }\end{array}$ & & & $\begin{array}{l}\text { Cambrex Bio Science Verviers S.P.R.L., } \\
\text { Verviers, Belgium PT-3003 }\end{array}$ \\
\hline Control & $\alpha-\mathrm{MEM}$ & $10 \% \mathrm{FCS}$ & $50 \mu \mathrm{g} / \mathrm{mL}$ of gentamicin \\
\hline
\end{tabular}

regularly with a light microscope. When the majority of cell bodies had become spherical and refractile, the neurogenic medium was removed and samples were collected. Cells were fixed with $4 \%$ paraformaldehyde and analyzed via immunohistochemistry, for the expression of neuronalspecific nuclei protein (NeuN; MAB377; Chemicon, Temecula, CA) and neural-specific enolase (NSE; sc-21738; Santa Cruz Biotechnology, Santa Cruz, CA). RNA from the samples was collected using Trizol reagent, and the expression of NSE was assessed by RT-PCR.

- Osteogenic/odontogenic differentiation: Cells were seeded on 24-well plates at 20,000 cells $/ \mathrm{cm}^{2}$. Subconfluent cultures were incubated in osteogenic medium (Table 1) for 3 weeks. Medium was changed every 2-3 days. Calcification of the extracellular matrix was checked via von Kossa staining. Differentiation was analyzed by immunohistochemistry and by RT-PCR for the expression of dentin sialophosphoprotein (DSPP).

- Adipogeneic differentiation: Cells were seeded on 24well plates at 20,000 cells $/ \mathrm{cm}^{2}$. Subconfluent cultures were incubated in the adipogenic medium (Table 1) for 3 or 6 weeks. Medium was changed every 2-3 days. Afterwards, cells were stained with oil red $\mathrm{O}$ stain. Further, adipogenic differentiation was analyzed via immunohistochemistry for the expression of glucose transporter-4 (GLUT4; E-20; Santa Cruz Biotechnology) and via RT-PCR for the expression of peroxisomeproliferating activated receptor $\gamma($ PPAR $\gamma 2)$ and GLUT4.

- Myogenetic differentiation: Cells were seeded on 24-well plates at $20,000 \mathrm{cells} / \mathrm{cm}^{2}$. The cells were cultured in myogenic medium (Table 1) for 3 or 6 weeks. Morphological changes were viewed via light microscopy after hematoxylin and eosin (H\&E) staining. Differentiation was confirmed via immunohistochemistry for the expression of myogenic differentiation protein (MyoD1; cat. no. 554130; PharMingen, San Diego, CA) and myosin heavy chain (MHC; ALD-58; Developmental Studies Hybridoma Bank, Iowa City, IA), and by RT-PCR for the expression of MyoD1.
- Chondrogenic differentiation: Chondrogenic differentiation was induced by using the "pellet culture" technique $^{19}$. Briefly stated, approximately 250,000 cells were placed in a $15-\mathrm{mL}$ polypropylene tube (Falcon), and centrifuged to pellet. Then, $0.5 \mathrm{~mL}$ of chondrogenic medium (PT-3003; Cambrex Bio Science, Verviers, Belgium) was added, freshly supplemented with $10 \mathrm{ng} / \mathrm{mL}$ of transforming growth factor- $\beta 3$ (TGF- $\beta 3$ ). Medium was changed every 3-4 days for 4 weeks. Pellets cultured in medium without TGF- $\beta 3$ were used as controls. All samples and controls were present fourfold. After 4 weeks, the pellets were fixed in $10 \%$ neutral buffered formalin, dehydrated in a series of ethanol, embedded in paraffin, and cut into 5- $\mu \mathrm{m}$ sections. After deparaffinization, the sections were evaluated via alcian blue staining, and immunohistochemistry for the expression of collagen type II (Col II; CIIC1; Developmental Studies Hybridoma Bank).

\section{von Kossa staining}

To assess the formation of a calcified extracellular matrix, cells were fixed with $10 \%$ formalin, stained with fresh 5\% silver nitrate $\left(\mathrm{AgNO}_{3}\right)$, washed with distilled water, developed with $5 \%$ sodium carbonate $\left(\mathrm{Na}_{2} \mathrm{CO}_{3}\right)$ in $25 \%$ formalin, and fixed with $5 \%$ sodium thiosulfate $\left(\mathrm{Na}_{2} \mathrm{~S}_{2} \mathrm{O}_{3}\right)$.

\section{Oil red $O$ staining}

Cells were fixed in $10 \%$ formalin for $60 \mathrm{~min}$ at room temperature. After washing with $70 \%$ ethanol, the cells were incubated in $2 \%(\mathrm{w} / \mathrm{v})$ oil red $\mathrm{O}$ reagent for $5 \mathrm{~min}$ at room temperature and washed in $70 \%$ ethanol and MilliQ water to remove the excess stain. Then, the cells were counterstained with hematoxylin for $2 \mathrm{~min}$.

\section{Alcian blue staining}

The slides obtained after chondrogenic differentiation were rehydrated in Milli-Q water. Then, the slides were 
Table 2. SPecific Markers for RT-PCR (Human)

\begin{tabular}{|c|c|c|}
\hline Situation & Marker & Primer \\
\hline Neurogenic differentiation & NSE & $\begin{array}{l}5^{\prime} \text {-AAGGACAAATACGGCAAGGA-3' } \\
5^{\prime} \text {-TGGACCAGGCAGCCCAATC-3' }\end{array}$ \\
\hline Osteogenic differentiation & DSPP & $\begin{array}{l}5^{\prime} \text {-GGCAGTGACTCAAAAGGAGC-3' } \\
5^{\prime} \text {-TGCTGTCACTGTCACTGCTG-3' }\end{array}$ \\
\hline Adipogenic differentiation & $\begin{array}{l}\text { PPAR } \gamma 2 \\
\text { GLUT4 }\end{array}$ & $\begin{array}{l}5^{\prime} \text {-CCAGAGCATGGTGCCTTCGCT-3' } \\
3^{\prime} \text {-CAGCAACCATTGGGTCAGCTC-3' } \\
5^{\prime} \text {-GGCATGTGTGGCTGTGCCATC-3' } \\
5^{\prime} \text {-GGGTTTCACCTCCTGCTCTAA-3' }\end{array}$ \\
\hline Myogenic differentiation & MyoD1 & $\begin{array}{l}5^{\prime} \text {-AAGCGCCATCTCTTGAGGTA-3' } \\
5^{\prime} \text {-GCGCCTTTATTTTGATCACC-3 }{ }^{\prime}\end{array}$ \\
\hline Positive control & GAPDH & $\begin{array}{l}5^{\prime} \text {-ACCACAGTCCATGCCATCAC-3' } \\
5^{\prime} \text {-TCCACCACCCTGTTG CTGTA-3' }\end{array}$ \\
\hline
\end{tabular}

pretreated with $3 \%$ acetic acid for $3 \mathrm{~min}$ and incubated for 30 min with $1 \%$ (w/v) alcian blue ( $\mathrm{pH} 1.0)$. Subsequently, the slides were counterstained by nuclear fast red for $5 \mathrm{~min}$ and washed in running tap water.

\section{Immunohistochemistry}

The cells cultured for the neurogenic, osteogenic/odontogenic, adipogenic, and myogenic differentiation were fixed for $15 \mathrm{~min}$ in $4 \%$ paraformaldehyde. The slides collected after chondrogenic differentiation were rehydrated and antigens were retrieved by heating to $70^{\circ} \mathrm{C}$ in a microwave oven for $10 \mathrm{~min}$, and incubating in $0.075 \%$ trypsin for $5 \mathrm{~min}$. Then, samples were washed twice in PBS and blocked with $5 \%$ bovine serum albumin (BSA), incubated for $1 \mathrm{~h}$ in $1 \%$ BSA containing the aforementioned specific antibodies, incubated with biotinylated secondary antibody for $45 \mathrm{~min}$, and stained with horseradish peroxidase conjugated Vectastain ABC staining kit (Vector Laboratories). Subsequently, the cells were incubated in DAB solution and intensified using $0.5 \% \mathrm{CuSO}_{4}$. Samples were counterstained with hematoxylin solution for $10 \mathrm{~s}$ and dehydrated through a graded series of ethanol.

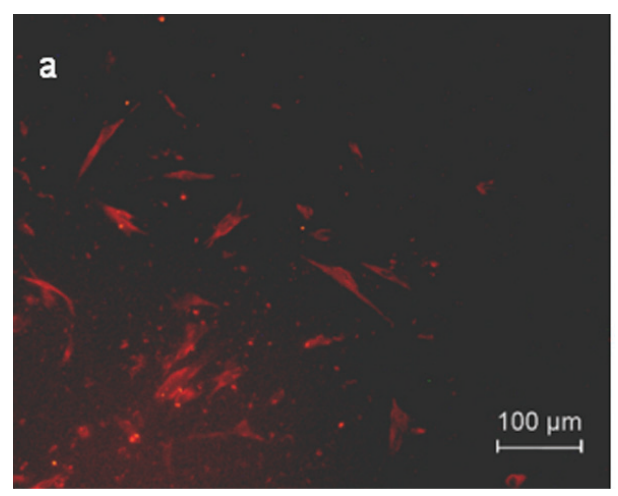

\section{$R T-P C R$}

Total cellular RNA was isolated using Trizol reagent (Gibco BRL). The extracted RNA was reverse transcribed by following conventional protocols. The produced cDNA was used as a template for RT-PCR. PCR reactions were performed using the human-specific sense and antisense primers which were designed according to published cDNA sequences of Genbank (Table 2). Parallel amplifications of glyceraldehyde-3-phosphate dehydrogenase (GAPDH) were performed to serve as positive reference. PCR products were separated by electrophoresis on a $1.5 \%$ agarose gel and were visualized by ultraviolet-induced fluorescence.

\section{RESULTS}

\section{Cell isolation and basic analysis}

After cryopreservation, only 2 cell cultures could be maintained for 25 passages. After incubation in osteogenic medium and von Kossa staining, only the most positively stained cell strain was selected for further experimentation. Both hDPSC-NB and hDPSC-NIH were showed 5-10\% positive staining for STRO-1 (Fig. 1).

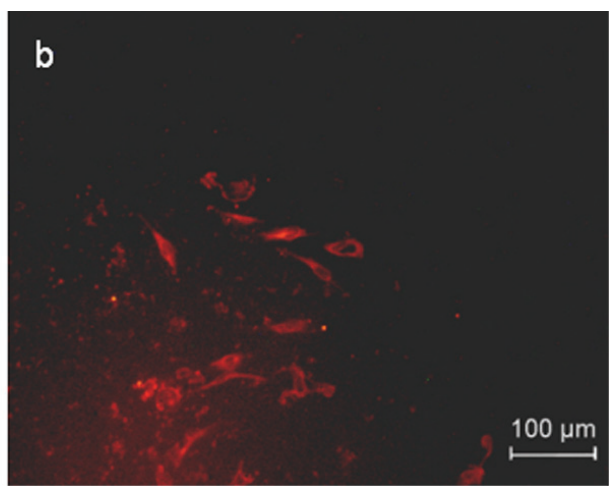

FIG. 1. Fluorescence micrograph of dental pulp cells, after immunoflurorescence staining for the stem cell marker STRO-1. Positive cells were stained red. (A) hDPSC-NB cells; (B) hDPSC-NIH cells. Color images available online at www.liebertpub.com/ten 


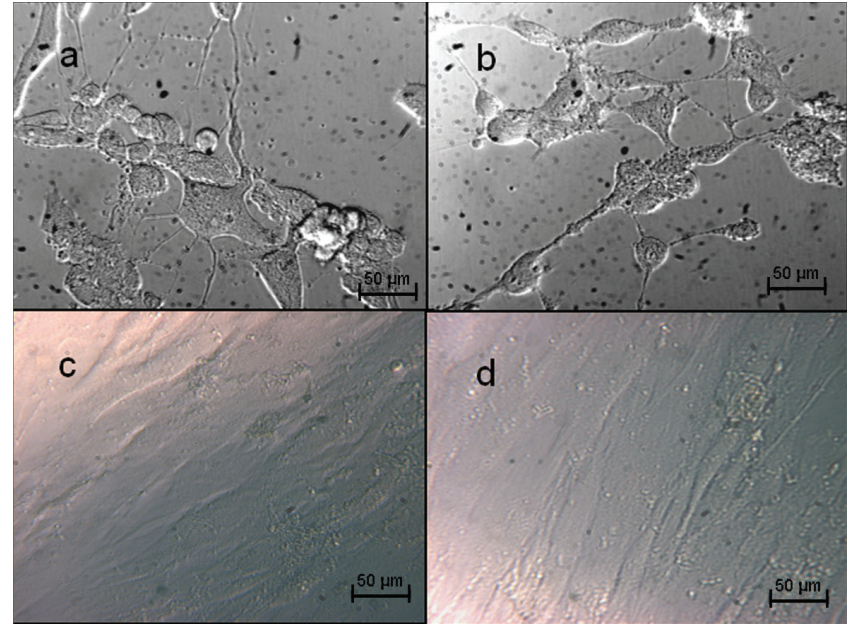

FIG. 2. Morphological changes of hDPSC after neurogenic differentiation. (A) hDPSC-NB sample; (B) hDPSC-NIH sample; (C) hDPSC-NB control; (D) hDPSC-NIH control. Color images available online at www.liebertpub.com/ten.

\section{Neurogenic differentiation}

Light microscopy showed that the cytoplasm of both hDPSC-NB and hDPSC-NIH retracted towards the nuclei $1 \mathrm{~h}$ after the neurogenic medium was added. After $5 \mathrm{~h}$, most of the cells showed a typical neuronal perikaryal appearance, that is, cell bodies had become increasingly spherical and refractile. The cell bodies had long cytoplasmic extensions, with secondary branches (Fig. 2A, B). Morphology of the control group remained unchanged (Fig. 2C, D).

Many cells with nerve cell-like morphology showed positive staining against NeuN (Fig. 3A, B) and NSE (Fig. 3E,
F). No positive staining of NeuN was observed in the control group (Fig. 3C, D), while only very limited numbers of cells of the control group showed positive staining against NSE (Fig. 3G, H). RT-PCR corroborated the staining, that is, abundant NSE expression was found in the sample group, whereas control groups showed weak expression only.

\section{Odontogenic/osteogenic differentiation}

After 3 weeks in culture with osteogenic medium, visual inspection showed that cells had proliferated and produced a dense extracellular matrix (ECM). Nodular structures were found, which were stained black via von Kossa staining (Fig. 4). There were more distinct nodules in hDPSC-NIH samples than in the hDPSC-NB samples. No effects were observed in the control group. Cells did not show the typical column shape of odontoblasts. The expression of DSPP in both sample groups was ascertained by immunohistochemistry (Fig. 4), and also RT-PCR showed DSPP expression in the experimental, but not in the control groups.

\section{Adipogenic differentiation}

No obvious morphological changes were found after 3 weeks induction, however some cells in both experimental groups showed an enlarged cell body when they were cultured in adipogenic medium for 6 weeks. Oil red Opositive lipid droplets were not found in any of the samples. In contrast, the expression of GLUT-4 was detected in hDPSC-NB and hDPSC-NIH (Fig. 5). The adipogenic phenotype was further confirmed by PT-PCR, where it was shown that PPAR $\gamma 2$ and GLUT-4 were expressed in both experimental groups, but not in the control groups.

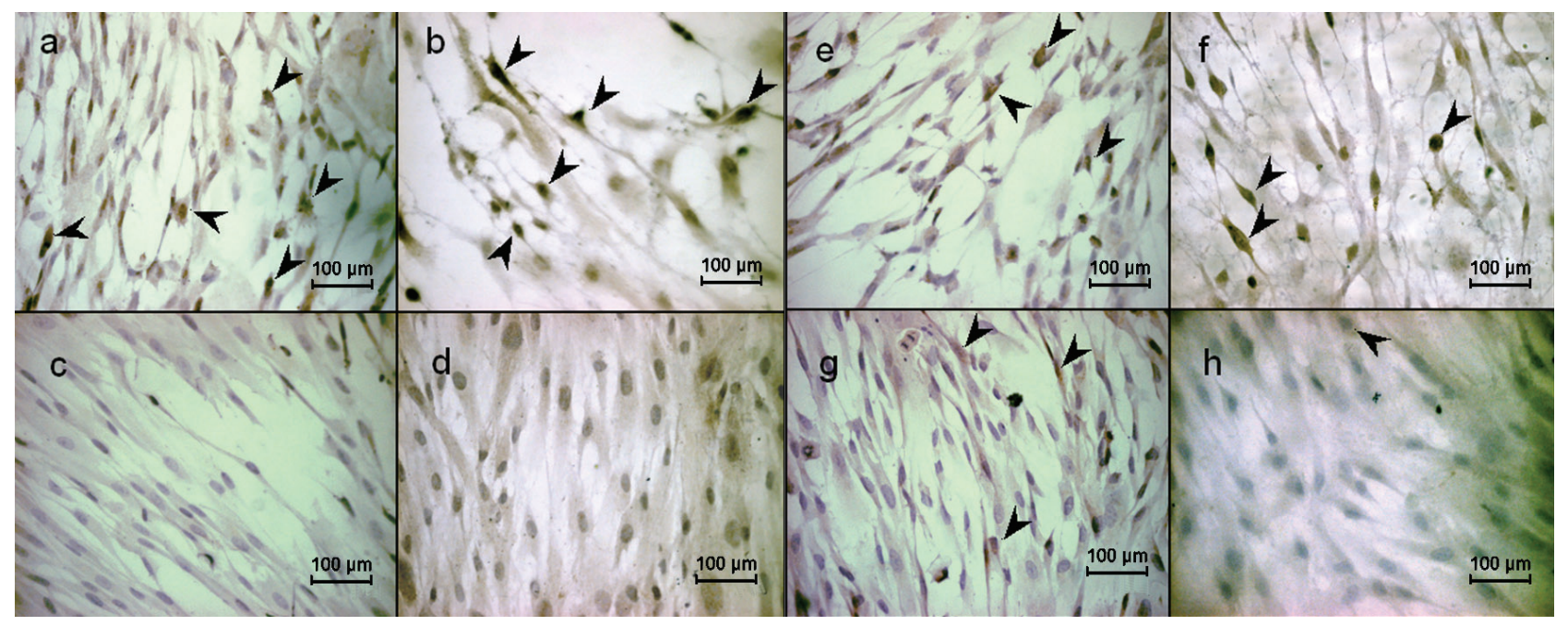

FIG. 3. Immunohistochemical staining for specific neurogenic markers after neurogenic differentiation (arrows indicate the positive cells). (A) hDPSC-NB sample (NeuN); (B) hDPSC-NIH sample (NeuN); (C) hDPSC-NB control (NeuN); (D) hDPSC-NIH control (NeuN); (E) hDPSC-NB sample (NSE); (F) hDPSC-NIH sample (NSE); (G) hDPSC-NB control (NSE); (H) hDPSC-NIH control (NSE). Color images available online at www.liebertpub.com/ten. 


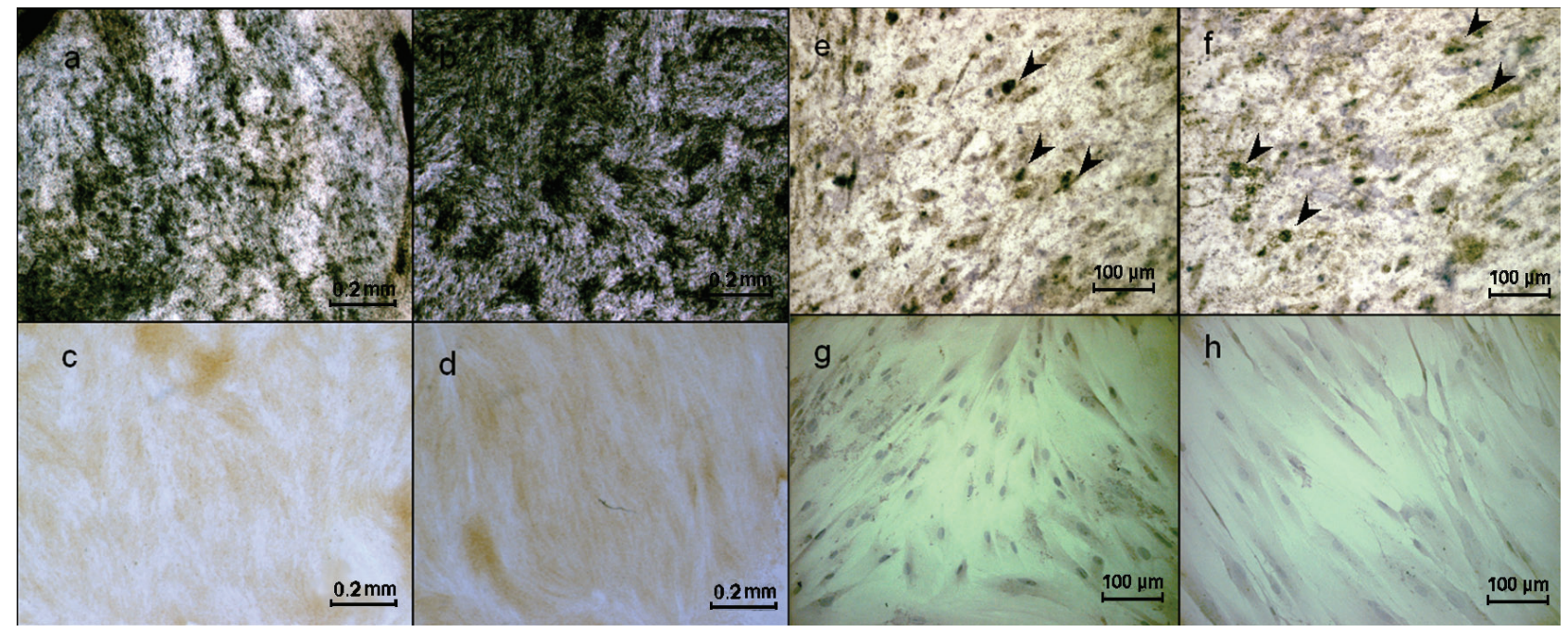

FIG. 4. Results after osteogenic differentiation. (A) hDPSC-NB sample (von Kossa staining); (B) hDPSC-NIH sample (von Kossa staining); (C) hDPSC-NB control (von Kossa staining); (D) hDPSC-NIH control (von Kossa staining); (E) hDPSC-NB sample (immunohistochemical staining for DSPP); (F) hDPSC-NIH sample (immunohistochemical staining for DSPP); (G) hDPSC-NB control (immunohistochemical staining for DSPP); (H) hDPSC-NIH control (immunohistochemical staining for DSPP). Color images available online at www.liebertpub.com/ten.

\section{Myogenic differentiation}

Light microscopy did not show differences after culture in myogenic medium for 3 weeks. However, at 6 weeks some of the cells had become elongated and showed a myoblast-like phenotype. This was most evident in the hDPSC-NB samples (Fig. 6). Still, no multinucleated cells could be observed. Immunohistochemistry showed positive staining for MyoD1 and MHC in both strains of hDPSC

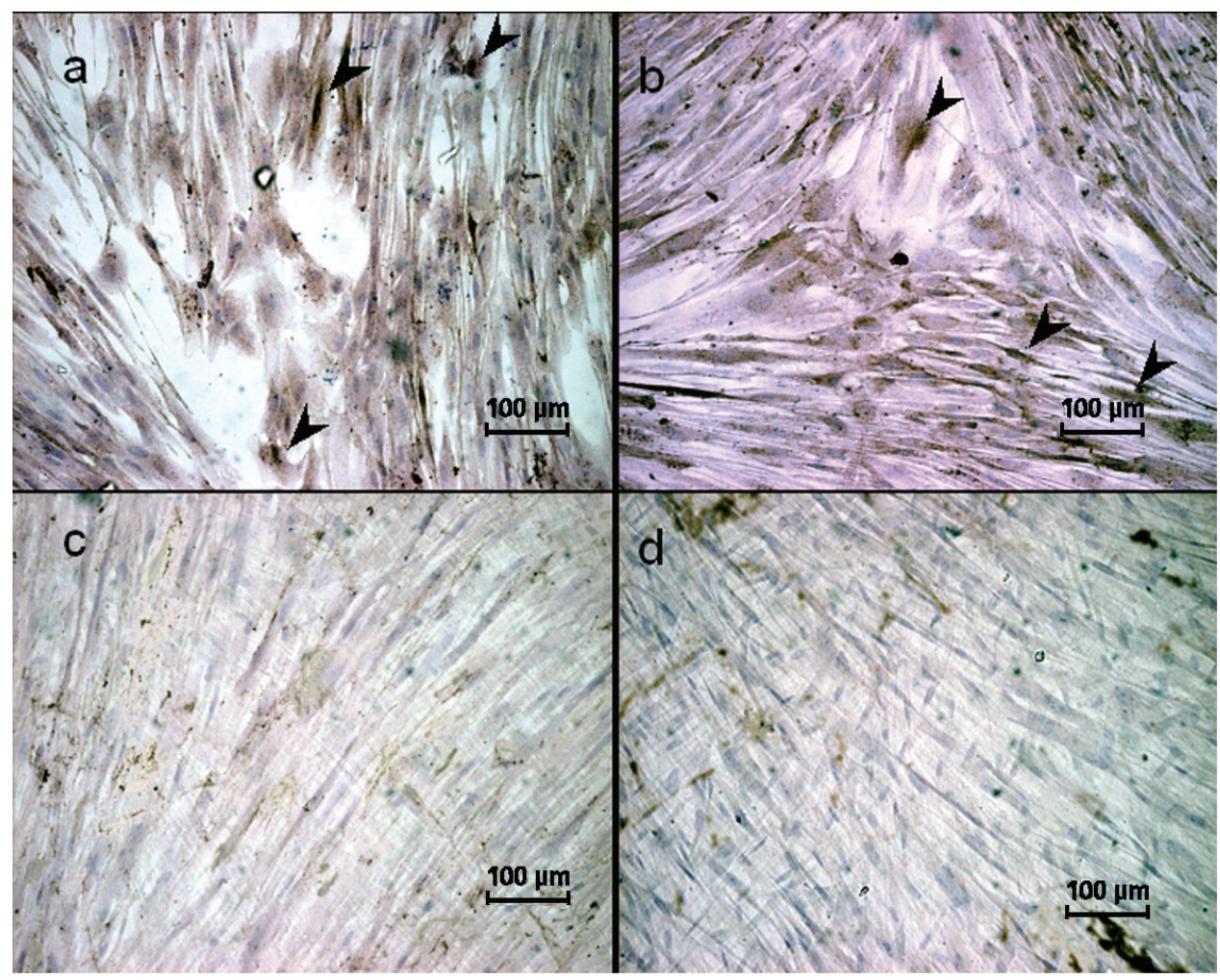

FIG. 5. Immunohistochemical staining for GLUT4 after adipogenic differentiation (arrows indicate the positive cells). (A) hDPSCNB sample; (B) hDPSC-NIH sample; (C) hDPSC-NB control; (D) hDPSC-NIH control. Color images available online at www .liebertpub.com/ten. 


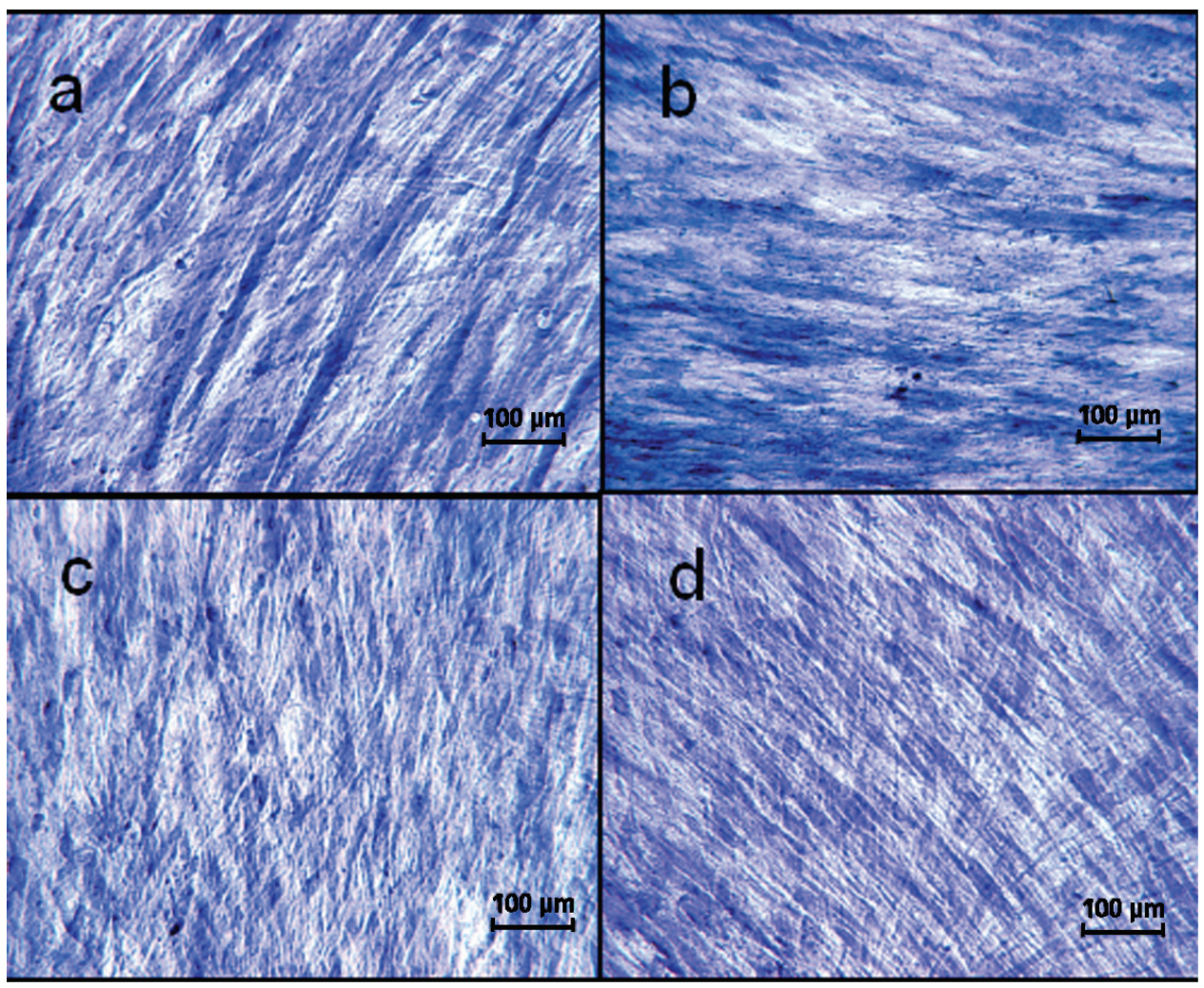

FIG. 6. H\&E staining of hDPSC after myogenic differentiation. (A) hDPSC-NB sample; (B) hDPSC-NIH sample; (C) hDPSC-NB control; (D) hDPSC-NIH control. Color images available online at www.liebertpub.com/ten.

(Fig. 7). The expression of MyoD1, and of MHC, was confirmed by RT-PCR. No expression was seen in the control groups.

\section{Chondrogenic differentiation}

All 4 pellets of both types of hDPSC showed a similar phenotype, and increased in size during the culture. The pellets formed by hDPSC-NIH were bigger than the pellets formed by hDPSC-NB. Pellets of the nonstimulated control groups were smaller and felt weaker during handling.

Histological examination of the cells pellets (Fig. 8) indicated that the pellets formed by hDPSC-NIH contained more cells than those of the hDPSC-NB. Most of the cells in the central region were rounded and separated by abundant ECM, while the periphery was built up by several layers of spindle-shaped cells. The bright blue staining of the ECM in the center of the pellets indicated the presence of highly sulfated glycosaminoglycans (GAGs). Closer inspection showed a distinct phenotypical difference between the 2 types of hDPSC, as the hDPSC-NIH samples showed a more homogeneously distributed alcian blue-positive ECM around the cells (Fig. 8). This structure more closely resembled the structure of cartilage, and constructs formed by bone marrow stem cells after chondrogenic induction ${ }^{19}$. Alcian blue staining was not detected in the controls.
Expression of collagen type II in the experimental groups was confirmed only via immunohistochemical staining (Fig. 8).

\section{DISCUSSION}

In this study, we analyzed the differentiation potential of human postnatal dental pulp stem cells toward the neurogenic, odontogenic/ osteogenic, adipogenic, myogenic, and chondrogenic pathways after cryopreservation. Two cell strains were used; hDPSC-NB selected directly derived from the pulp tissue of a wisdom tooth, and hDPSC-NIH obtained from NIH. The latter were described previously to be able to differentiate to odontoblast-like and adipocytelike cells ${ }^{18}$; and thus were regarded as positive controls for our study. We investigated phenotypes according to morphology, and the expression of specific markers by immunohistochemistry and RT-PCR. It was shown in a systematic way (within 1 study) that 5 different pathways could be obtained from one primary culture of dental pulp stem cells, including chondrogenic and myogenic differentiation, even after cryopreservation.

The selection of dental pulp stem cells from the third molar can be an easy accessible choice for tissue engineering. Many wisdom teeth cannot erupt at the appropriate 


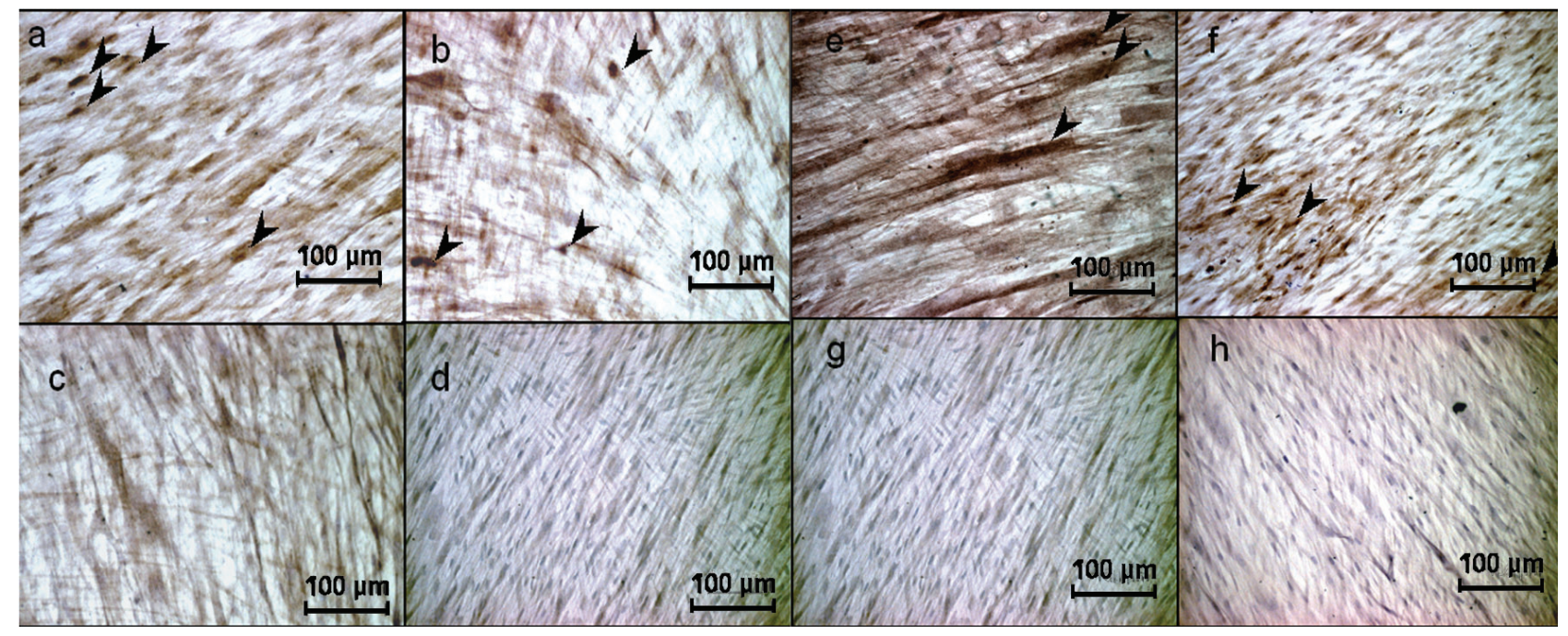

FIG. 7. Immunohistochemical staining after myogenic differentiation (arrows indicate the positive cells). (A) hDPSC-NB sample (MyoD1); (B) hDPSC-NIH sample (MyoD1); (C) hDPSC-NB control (MyoD1); (D) hDPSC-NIH control (MyoD1); (E) hDPSC-NB sample (MHC); (F) hDPSC-NIH sample (MHC); (G) hDPSC-NB control (MHC); (H) hDPSC-NIH control (MHC). Color images available online at www.liebertpub.com/ten.

position and stay impacted because of inadequate jawbone space. Many factors, such as gender, race, and habitation, are related with the incidence of impacted wisdom teeth, ${ }^{20,21}$ but about $70 \%$ of people have at least one impacted wisdom tooth, ${ }^{22,23}$ potentially damaging to surrounding soft tissues as well as to neighboring teeth. Although some controversy exists, preventive extraction is considered to be an acceptable solution. ${ }^{24}$ In theory, as the last erupted teeth, wisdom teeth have the youngest pulp and thus contain most unspecialized cells. Further, their autologous nature will not elicit an undesirable immunological response, when these cells are used in tissue engineering strategies. Recently, it was shown that also the periodontal ligament, which is commonly present around a tooth after extraction, could also serve as a similar source for the retrieval of adult stem cells. ${ }^{25}$

Considering neurogenic differentiation, a striking morphological difference was found in the treated samples versus the controls. Cells formed long extensions with secondary branches typical for neurons. In conjunction with morphological changes, we examined the expression of NeuN and NSE. The expression of NeuN is known in most neuronal cell types throughout the nervous system, including cerebral cortex, spinal cord, and peripheral nervous system. ${ }^{26}$ NSE is first localized in the neuronal cytoplasm and is supposed to serve as a growth factor in neurons. ${ }^{27}$ In our case, the expression of both NeuN and NSE as markers for neuronal phenotype together with the observed morphological changes undoubtedly confirmed neurogenic differentiation. Still, this does not mean the cells can also function as neuron. Further experimentation in this field is required in animal models aiming at repairing neuronal defects or combating, for instance, Parkinson's disease. ${ }^{28}$
When regarding the differentiation to hard tissue, we used the terms odontogenic/ osteogenic because the inductive medium applied for odontogenic differentiation is normally used for osteogenic purposes. Although the physical properties are different, dentin and bone are very similar tissues with numerous mutual components. Also, the reactions to molecular signals are often analogous. ${ }^{29}$ To ensure that the cells differentiated toward an odontogenic phenotype, DSPP was chosen as a marker protein. Other markers, such as dentin matrix protein-1 (DMP-1) ${ }^{30}$ could also have been used, but have the disadvantage that these are also expressed in bone. Though no marker currently available is $100 \%$ specific for dentin, DSPP plays an important role in dentinogenesis and is abundantly expressed in dentin, and only trace expression was detected in bone. ${ }^{31}$ Although all our cell cultures were DSPP positive, it was not possible to observe the typical column-shaped morphology of an odontoblast. To obtain a specific odontoblast-like appearance, the cells would require the guidance of a surrounding tissue or biomimetically designed scaffold material.

For studying adipogenic differentiation, the widely known adipogenic-specific markers PPAR $\gamma 2$ and GLUT-4 were chosen, and cultures proved positive for both. PPAR $\gamma 2$ is a marker for adipogenic differentiation because it mainly is expressed in fat tissue and can activate adipocyte differentiation. ${ }^{32}$ GLUT-4 is also regarded as an adipogenic marker. ${ }^{33}$ However, the oil red $\mathrm{O}$ staining, which is an indicator for lipid accumulation, failed to reveal intracellular lipid droplets. This was in contrast with previous studies. ${ }^{18}$ The different formulations of their inductive medium (supplemented with $0.5 \mathrm{mM}$ isobutylmethylxanthine, $0.5 \mu \mathrm{M}$ hydrocortisone, and $60 \mu \mathrm{M}$ indomethancin) may be the 

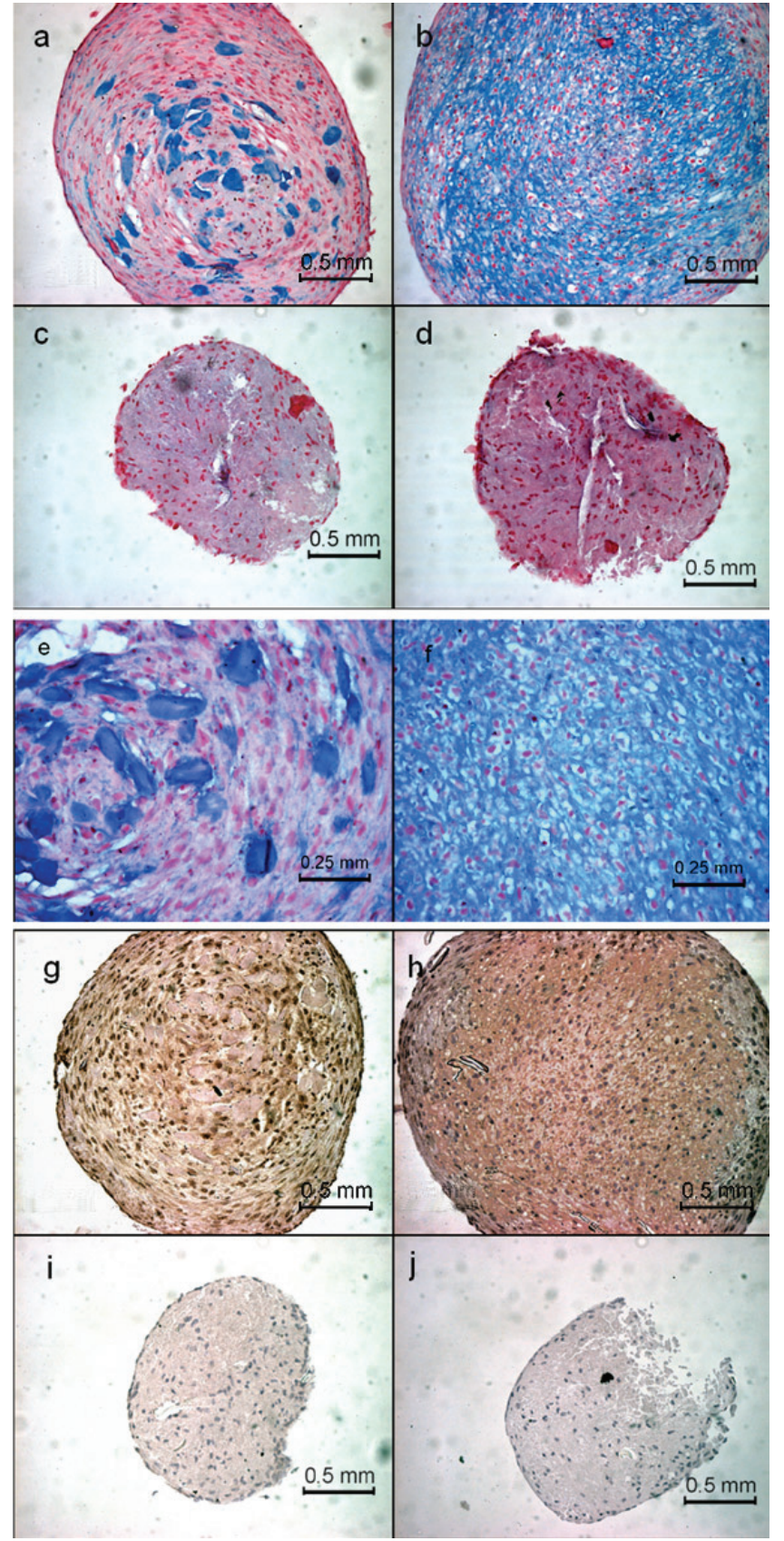

FIG. 8. Results after chondrogenic differentiation. (A) hDPSCNB sample (alcian blue staining); (B) hDPSC-NIH sample (alcian blue staining); (C) hDPSC-NB control (alcian blue staining); (D) hDPSC-NIH control (alcian blue staining); (E) hDPSC-NB sample (alcian blue staining, higher magnification); (F) hDPSC-NIH sample (alcian blue staining, higher magnification). (G) hDPSC-NB sample (immunohistochemical staining for collagen II); (H) hDPSCNIH sample (immunohistochemical staining for collagen II); (I) hDPSC-NB control (immunohistochemical staining for collagen II); (J) hDPSC-NIH control (immunohistochemical staining for collagen II). Color images available online at www.liebertpub.com/ten. reason of this discrepancy, although the formula utilized in our lab is also commonly used for adipogenic induction.

MyoD1 is active early in the myogenic lineage in order to establish myoblast identity, ${ }^{34}$ whereas $\mathrm{MHC}$ is regarded as a late differentiation marker. ${ }^{35}$ In this research, both MyoD1 and MHC markers proved positive. Still, no multinucleated cell was observed in our cell cultures. The presence of multiple nuclei is a specific characteristic for terminal differentiation, after myoblast fusion. The reason that we do not observe this in our study may be that the culture time was limited.

Finally, the chondrogenic lineage was evaluated. Alcian blue staining showed that both types of human dental pulp cells were able to form a structure with a well-organized ECM rich in sulfated progeoglycans and type II collagens. However, large differences were seen between the hDPSCNB and hDPSC-NIH cells. The tissue formed by hDPSCNIH showed more resemblance to the appearance of natural cartilage, and to previous reports on bone marrow stem cells after chondrogenic differentiation. ${ }^{19}$ This difference in behavior is probably due to the fact that various cell types are present within the dental pulp. ${ }^{36}$ The hDPSC-NIH consist of a highly selected cell population, whereas hDPSC-NB, even after prolonged culturing most likely still form a more diverse group of cells.

Nowadays, adult stem cells have been identified in many tissues, including bone marrow, brain, skin, muscle, adipose tissue, etc. These cells all share the two basic stem cell characteristics of long-term self-renewal, and ability to differentiate into matured cell types with characteristic morphologies and specialized functionality.

When comparing our study to recent literature, the multipotent ability of dental pulp cells was also evaluated in recent studies. One investigation describes $\mathrm{C}-\mathrm{kit}^{+} / \mathrm{CD} 34^{+} /$ STRO- $1^{+}$cells sorted from deciduous dental pulp cells, could be differentiated into osteoblast-like or adipocyte-like cells. In the same population, myotube fusion was observed when the sorted cells were cocultured in ATCC medium with mouse myogenic $\mathrm{C} 2 \mathrm{C} 12$ cells. ${ }^{37}$ Another study proved that the third passage of human dental pulp cells could differentiate toward the adipogenic and osteogenic. ${ }^{38}$ Such results corroborate our study, although no crytopreservation was used. Cryopreservation is the most commonly used method for cell storage. Cells can still maintain their basic properties for more than 10 years in liquid nitrogen. ${ }^{39}$ To achieve long-term usage of cells for tissue regeneration, it is essential to prove the stem cells can keep their differentiation potential after such a procedure.

With regard to the content of a pulp, it is obvious that odontoblasts and nerve cells are the most commonly differentiated cell types. Only occasionally adipocytes, and no myoblasts or cartilage cells are found ${ }^{36}$ Adult dental pulp stem cells appear capable to differentiate into more pathways than their origin, such as the neuron-, odontoblast-, 
adipocyte-, myoblast-, and chondrocyte-like phenotypes. However, there is still debate regarding this property. Some studies postulate that ASC plasticity may be due to fusion with preexisting differentiated cells during in vivo analysis. Others suggested that the multilineage potential of ASCs in muscle and fat tissue actually is the consequence of the presence of blood vessels. Bone marrow stem cells might reach peripheral tissue via the vascular system. On the other hand, the occurrence of bone marrow stem cells in peripheral blood is still questionable. ${ }^{40}$ Although a dental pulp is small and bone marrow stem cells are $\operatorname{rare}^{41}(1$ in 10,000 to 15,000 cells in the bone marrow), their influence still needs to be considered.

In conclusion, our results demonstrated that dental pulp cells from third molars could serve as a source of multipotential stem cells, applicable for autologous tissue regeneration and cell-based therapies, even after cryopreservation. Both types of dental pulp cells studied here resulted in analogous multilineage differentiation. However, as the molecular basis of plasticity is still not clearly demonstrated, further analyses are necessary before clinical application can commence.

\section{ACKNOWLEDGMENTS}

Biopsies kindly provided by Dr. Philip A. Van Damme, Department of Oral and Maxillofacial Surgery, Radboud University Nijmegen Medical Centre. DSPP antiserum was kindly provided by Dr. Larry W. Fisher, National Institutes of Health/ NIDCR, Bethesda, MD. The ALD-58 developed by Donald A Fischman and CIIC1 developed by Rikard Holmdahl/Kristofer Rubin were obtained from the developmental Studies Hybridoma Bank developed under the auspices of the NICHD and maintained by The University of Iowa, Department of Biological Sciences, Iowa City, IA 52242. This work was supported by The Royal Netherlands Academy of Arts and Sciences (KNAW; NO. WHOCC 96955).

\section{REFERENCES}

1. Kirschstein, R., and Skirboll, L.R. Stem cells: scientific progress and future research directions. Report by National Institutes of Health. 2001.

2. Spangrude, G.J., Smith, L., Uchida, N., Ikuta, K., Heimfeld, S., Friedman, J., and Weissman, I.L. Mouse hematopoietic stem cells. Blood 78, 1395, 1991.

3. Bianco, P., Riminucci, M., Gronthos, S., and Robey, P.G. Bone marrow stromal stem cells: nature, biology, and potential applications. Stem Cells 19, 180, 2001.

4. Morshead, C.M., Reynolds, B.A., Craig, C.G., McBurney, M.W., Staines, W.A., Morassutti, D., Weiss, S., and van der Kooy, D. Neural stem cells in the adult mammalian forebrain: a relatively quiescent subpopulation of subependymal cells. Neuron 13, 1071, 1994.
5. Jones, P.H., and Watt, F.M. Separation of human epidermal stem cells from transit amplifying cells on the basis of differences in integrin function and expression. Cell 73, 713, 1993.

6. Bosch, P., Musgrave, D.S., Lee, J.Y., Cummins, J., Shuler, T., Ghivizzani, T.C., Evans, T., and Robbins, T.D., Huard. Osteoprogenitor cells within skeletal muscle. J. Orthop. Res. 18, 933, 2000.

7. Gimble, J., and Guilak, F. Adipose-derived adult stem cells: isolation, characterization, and differentiation potential. Cytotherapy 5, 362, 2003.

8. Woodbury, D., Schwarz, E.J., Prockop, D.J., and Black, I.B. Adult rat and human bone marrow stromal cells differentiate into neurons. J. Neurosci. Res. 61, 364, 2000.

9. Pittenger, M.F., Mackay, A.M., Beck, S.C., Jaiswal, R.K., Douglas, R., Mosca, J.D., Moorman, M.A., Simonetti, D.W., Craig, S., and Marshak, D.R. Multilineage potential of adult human mesenchymal stem cells. Science 284, 143, 1999.

10. Liechty, K.W., MacKenzie, T.C., Shaaban, A.F., Radu, A., Moseley, A.M., Deans, R., Marshak, D.R., and Flake, A.W. Human mesenchymal stem cells engraft and demonstrate sitespecific differentiation after in utero transplantation in sheep. Nat. Med. 6, 1282, 2000.

11. Galli, R., Borello, U., Gritti, A., Minasi, M.G., Bjornson, C., Coletta, M., Mora, M., De Angelis, M.G., Fiocco, R., Cossu, G., and Vescovi, A.L. Skeletal myogenic potential of human and mouse neural stem cells. Nat. Neurosci. 3, 986, 2000.

12. Goodell, M.A., Jackson, K.A., Majka, S.M., Mi, T., Wang, H., Pocius, J., Hartley, C.J., Majesky, M.W., Entman, M.L., Michael, L.H., and Hirschi, K.K. Stem cell plasticity in muscle and bone marrow. Ann. NY Acad. Sci. 938, 208, 2001.

13. Zuk, P.A., Zhu, M., Ashjian, P., De Ugarte, D.A., Huang, J.I., Mizuno, H., Alfonso, Z.C., Fraser, J.K., Benhaim, P., and Hedrick, M.H. Human adipose tissue is a source of multipotent stem cells. Mol. Biol. Cell 13, 4279, 2002.

14. Brazelton, T.R., Rossi, F.M., Keshet, G.I., and Blau, H.M. From marrow to brain: expression of neuronal phenotypes in adult mice. Science 290, 1775, 2000.

15. Anderson, D.J., Gage, F.H., and Weissman, I.L. Can stem cells cross lineage boundaries? Nat. Med. 7, 393, 2001.

16. Bianco, P., and Cossu, G. Uno, nessuno e centomila: searching for the identity of mesodermal progenitors. Exp. Cell Res. 251, 257, 1999.

17. Gronthos, S.M., Mankani, J., Brahim, P., Gehron Robey, and S. Shi. Postnatal human dental pulp stem cells (Dental pulp cells of rat) in vitro and in vivo. Proc. Natl. Acad. Sci. USA. 97, 13625, 2000.

18. Gronthos, S., Brahim, J., Li, W., Fisher, L.W., Cherman, N., Boyde, A., DenBesten, P., Robey, P.G., and Shi, S. Stem cell properties of human dental pulp stem cells. J. Dent. Res. 81, 531, 2002.

19. Johnstone, B., Hering, T.M., Caplan, A.I., Goldberg, V.M., and Yoo, J.U. In vitro chondrogenesis of bone marrow-derived mesenchymal progenitor cells. Exp. Cell Res. 238, 265, 1998.

20. Kruger, E., Thomson, W.M., and Konthasinghe, P. Third molar outcomes from age 18 to 26: findings from a populationbased New Zealand longitudinal study. Oral Surg. Oral Med. Oral Pathol. Oral Radiol. Endod. 92, 150, 2001. 
21. Olasoji, H.O., and Odusanya, S.A. Comparative study of third molar impaction in rural and urban areas of South-Western Nigeria. Odontostomatol. Trop. 23, 25, 2000.

22. Morris, C.R., and Jerman, A.C. Panoramic radiograph survey: a study of embedded third molars. J. Oral Surg. 29, 122, 1971.

23. Hugoson, A., and Kugelberg, C.F. The prevalence of third molars in a Swedish population. An epidemiological study. Community Dent. Health 5, 121, 1988.

24. Kaminishi, R.M., and Kaminishi, K.S. New considerations in the treatment of compromised third molars. J. Calif. Dent. Assoc. 32, 823, 2004.

25. Shi, S., Bartold, P.M., Miura, M., Seo, B.M., Robey, P.G., and Gronthos, S. The efficacy of mesenchymal stem cells to regenerate and repair dental structures. Orthod. Craniofac. Res. 8, 191, 2005

26. Mullen, R.J., Buck, C.R., and Smith, A.M. NeuN, a neuronal specific nuclear protein in vertebrates. Development 116, 201, 1992.

27. Mandel, G., and McKinnon, D. Molecular basis of neuralspecific gene expression. Annu. Rev. Neurosci. 16, 323, 1993.

28. Kuszpit, K., Nosrat, I.V., Smith, C.A., and Nosrat, C.A. Biological tissue-engineering: dental pulp cells as a novel source of cells for transplantation therapy in Parkinson's disease. Abstract 32nd Annual Meeting and Exhibition of the AADR, March 12-15, 2003.

29. Qin, C., Baba, O., and Butler, W.T. Post-translational modifications of sibling proteins and their roles in osteogenesis and dentinogenesis. Crit. Rev. Oral Biol. Med. 15, 126, 2004.

30. Feng, J.Q., Huang, H., Lu, Y., Ye, L., Xie, Y., Tsutsui, T.W., Kunieda, T., Castranio, T., Scott, G., Bonewald, L.B., and Mishina, Y. The Dentin matrix protein 1 (Dmp1) is specifically expressed in mineralized, but not soft, tissues during development. J. Dent. Res. 82, 776, 2003.

31. Qin, C., Brunn, J.C., Cadena, E., Ridall, A., Tsujigiwa, H., Nagatsuka, H., Nagai, N., and Butler, W.T. The expression of dentin sialophosphoprotein gene in bone. J. Dent. Res. 81, 392, 2002.

32. Moerman, E.J., Teng, K., Lipschitz, D.A., and Lecka-Czernik, B. Aging activates adipogenic and suppresses osteogenic programs in mesenchymal marrow stroma/stem cells: the role of PPAR-gamma2 transcription factor and TGF-beta/BMP signaling pathways. Aging Cell 3, 379, 2004.

33. Fabres-Machado, U., and Saito, M. The effect of adipose cell size on the measurement of GLUT 4 in white adipose tissue of obese mice. Braz. J. Med. Biol. Res. 28, 369, 1995.
34. Weintraub, H., Davis, R., Tapscott, S., Thayer, M., Krause, M., Benezra, R., Blackwell, T.K., Turner, D., Rupp, R., and Hollenberg, S. The myoD gene family: nodal point during specification of the muscle cell lineage. Science 251, 761, 1991.

35. Silberstein, L., Webster, S.G., Travis, M., and Blau, H.M. Developmental progression of myosin gene expression in cultured muscle cells. Cell 46, 1075, 1986.

36. Ten Cate, R. Oral Histology: Development, Structure, and Function, 5th ed. St. Louis: CV Mosby, 1998.

37. Laino, G., Graziano, A., d'Aquino, R., Pirozzi, G., Lanza, V., Valiante, S., De. Rosa, A., Naro, F., Vivarelli, E., and Papaccio, G. An approachable human adult stem cell source for hard-tissue engineering. J. Cell Physiol. 206, 693, 2006.

38. Pierdomenico, L., Bonsi, L., Calvitti, M., Rondelli, D., Arpinati, M., Chirumbolo, G., Becchetti, E., Marchionni, C., Alviano, F., Fossati, V., Staffolani, N., Franchina, M., Grossi, A., and Bagnara, GP. Multipotent mesenchymal stem cells with immunosuppressive activity can be easily isolated from dental pulp. Transplantation 80, 836, 2005.

39. Mugishima, H., Harada, K., Chin, M., Suzuki, T., Takagi, K., Hayakawa, S., Sato, K., Klein, J.P., and Gale, R.P. Effects of long-term cryopreservation on hematopoietic progenitor cells in umbilical cord blood. Bone Marrow Transplant. 23, 395, 1999.

40. Lazarus, H.M., Haynesworth, S.E., Gerson, S.L., and Caplan, A.I. Human bone marrow-derived mesenchymal (stromal) progenitor cells (MPCs) cannot be recovered from peripheral blood progenitor cell collections. J. Hematother 6, 447, 1997.

41. Suva, D., Garavaglia, G., Menetrey, J., Chapuis, B., Hoffmeyer, P., Bernheim, L., and Kindler, V. Non-hematopoietic human bone marrow contains long-lasting, pluripotential mesenchymal stem cells. J. Cell Physiol. 198, 110, 2004.

Address reprint requests to: John A. Jansen, D.D.S., Ph.D. Radboud University Nijmegen Medical Centre Department of Periodontology and Biomaterials

P.O. Box 9101

6500 HB Nijmegen, The Netherlands

E-mail: J.Jansen@dent.umcn.nl 
